\title{
ANÁLISE BIBLIOMÉTRICA SOBRE PRÁTICAS DE GESTÃo SOCIOAMBIENTAL NA PEQUENA EMPRESA ${ }^{1}$
}

\author{
Marcelo Augusto Viana Pereira ${ }^{2}$ \\ mv_contador@hotmail.com
}

Márcia Athayde Moreira ${ }^{3}$

athayde.marcia@gmail.com

\begin{abstract}
Resumo
A gestão socioambiental representa um dos maiores desafios das organizações, orientado a conciliar interesses econômico, social e ambiental. Nesse cenário, merecem destaque os pequenos empreendedores, que, pelos mais diversos motivos, têm encontrado dificuldades de realizar ações de natureza socioambiental. Desse modo, esta pesquisa se propõe a identificar, a partir de análise bibliométrica dos Anais do EGEPE (2000 a 2016), os principais aspectos da gestão socioambiental que estão sendo tratados nas micro e pequenas empresas brasileiras. Foram identificados 21 artigos publicados nos Anais do evento que abordam o tema gestão socioambiental, sobre os quais se procedeu a uma análise quantitativa e qualitativa. Sob o ponto de vista quantitativo, os resultados observados mostram que o tema ainda tem sido pouco discutido no âmbito das micro e pequenas empresas, mas vem ganhando força, onde destacam-se as instituições de ensino superior públicas, notadamente da região sul do Brasil, como as mais produtivas no tema. Sob o ponto de vista qualitativo foram identificadas quatro categorias principais de pesquisas envolvendo o tema as MPEs, tendo sido observado uma tendência recente de estudar as MPEs sob a ótica da estratégia em implantar ações de natureza socioambiental. Entende-se necessário uma maior discussão de práticas sustentáveis dentro das organizações, gerando conhecimento acadêmico e interação social para maior conscientização por parte de micro e pequenos empreendedores, governo, consumidores e demais stakeholders.
\end{abstract}

Palavras-chave: Gestão socioambiental. Pequenas Empresas. Empreendedorismo. EGEPE.

\section{BIBLIOMETRIC ANALYSIS ON SOCIO-ENVIRONMENTAL MANAGEMENT PRACTICES IN SMALL COMPANY}

\begin{abstract}
Socio-environmental management represents one of the greatest challenges facing organizations, aimed at reconciling economic, social and environmental interests. In this scenario, small entrepreneurs deserve to be highlighted, who, for the most diverse reasons, have encountered difficulties in carrying out actions of a socioenvironmental nature. Thus, this research proposes to identify, from a bibliometric analysis of the Annals of EGEPE (2000 to 2016), the main aspects of social and environmental management that are being addressed in micro and small Brazilian companies. We identified 21 articles published in the Annals of the event that address the theme of social and environmental management, on which a quantitative and qualitative analysis was carried out. From the quantitative point of view, the observed results show that the subject has still been little discussed in the scope of micro and small companies, but it has been gaining strength, where the public higher education institutions, notably the southern region of Brazil, as the most productive in the theme. From the qualitative point of view, four main categories of research involving the theme of MSM were identified, and a recent tendency to study MSM from the point of view of the strategy in implementing social and environmental actions was observed. It is understood that a greater discussion of sustainable practices within organizations is necessary, generating academic knowledge and social interaction for greater awareness among micro and small entrepreneurs, government, consumers and other stakeholders.
\end{abstract}

Keywords: Socio-environmental management. Small companies. Entrepreneurship. EGEPE.

\footnotetext{
${ }^{1}$ A primeira versão deste artigo foi apresentada no IX Colóquio Organizações, Desenvolvimento e Sustentabilidade (2018).

${ }^{2}$ Bacharel em Ciências Contábeis, mestrando em Administração Gestão Organizacional pela Universidade da Amazônia - UNAMA.

${ }^{3}$ Doutora em Controladoria e Contabilidade pela Universidade de São Paulo - USP. Professora e pesquisadora do Programa de Mestrado e Doutorado em Administração da Universidade da Amazônia - PPAD/Unama.
} 


\section{INTRODUÇÃO}

É possível dizer que a gestão socioambiental é um dos maiores desafios que o mundo organizacional enfrenta atualmente. Desde a década de 70, as ideias de preservação do meio ambiente vêm sendo difundidas por meio de pesquisas e convenções internacionais na tentativa de conscientizar governos, empresários e sociedade, a exemplo da RIO 92 (1992), o protocolo de Kyoto (1997), Rio +10 (2002), Conferência de Copenhague (2009) e Rio +20 (2012).

Nesse cenário, observa-se que a partir dos anos 2000, a gestão socioambiental é mais bem consolidada, pois já se admite que, a promoção do desenvolvimento sustentável é elemento indissociável do aspecto social, econômico e ambiental e intrinsecamente relacionado com a sustentabilidade empresarial de longo prazo, no qual as questões ambientais possuírem interface com as questões sociais e vice-versa (BOSSLE, 2008).

A discussão permanece no âmbito nacional e internacional, em organizações situadas em países desenvolvidos e subdesenvolvidos, desafiando-as a obter soluções para a redução dos impactos ambientais, sem que isso implique a perda do foco na produção e competitividade. $\mathrm{O}$ novo conceito de gestão empresarial deixa, com isso, de focar suas atenções apenas no interesse dos acionistas e passa a valorizar também as relações com o meio ambiente e todos os demais stakeholders que contribuem para o sucesso organizacional (TACHIZAWA, 2005).

Dessa forma, a gestão ambiental e a responsabilidade social destacam-se como instrumentos gerenciais para a criação de condições de competitividade às organizações, independente do seu segmento econômico e porte. Assim, com o passar dos anos, percebe-se que a gestão socioambiental é uma prática que vem se desenvolvendo cada vez mais entre as empresas, ante os benefícios percebidos, não só à própria organização, mas ao meio ambiente e à sociedade. Nesse cenário, destacam-se as pequenas empresas, um segmento que antes alijado do processo de gestão socioambiental, crescentemente se apresenta como mais inclinado à adoção da postura, a despeito das dificuldades de gestão por que passam.

As pequenas empresas, que representam 98,5\% do total de empresas privadas brasileiras, respondem por $27 \%$ do PIB e são responsáveis por $54 \%$ do total de empregos formais existentes no país (SEBRAE, 2018), sofrem com a falta de ações que possam conciliar as atividades econômicas com o desenvolvimento sustentável, em um cenário onde a ausência de gestão profissional efetiva e de maiores controles financeiros e operacionais impede esse grupo de empresas de pensarem e praticarem uma gestão voltada para o desenvolvimento sustentável. 
Assim, dada a importância da gestão socioambiental para a sociedade e a necessidade de que todas as organizações a adotem como prática, independente do porte, com ênfase especial no incentivo à que pequenas empresas se engajem em ações de responsabilidade socioambiental, se estabelece a questão que norteará essa pesquisa: quais os principais aspectos da gestão socioambiental estão sendo tratadas nas micro e pequenas empresas

\section{Brasileiras?}

Para responder à questão de pesquisa, o objetivo desse trabalho é o de realizar uma análise bibliométrica nos Anais dos Encontros de Estudos sobre Empreendedorismo e Gestão de Pequenas Empresas - EGEPE, desde sua primeira edição no ano 2000 até sua última edição realizada no ano de 2016, a fim de conhecer os principais temas que vêm relacionando a gestão socioambiental às pequenas empresas, tendo como foco compreender como a administração vem discutindo e colaborando para o desenvolvimento de ações de natureza social e ambiental entre as pequenas empresas no Brasil.

A motivação para a realização dessa pesquisa se dá por algumas questões: gestão social e ambiental precisa ser pensada por todas as empresas, uma vez que o tema vem, a cada ano, ganhando destaque na sociedade e, por isso, novos estudos são realizados com intuito de verificar como as empresas estão contribuindo para a preservação do meio ambiente e dos recursos naturais e como essas práticas podem trazer retornos, tais como redução de custos, melhora da receita e da imagem diante dos clientes e demais stakeholders da organização. A adoção da gestão socioambiental pelas pequenas empresas pode trazer vários benefícios à sociedade em geral, devido a sua representatividade e capilaridade. Contribui para a discussão acadêmica emergente sobre micro e pequenas empresas e seu papel social, notadamente em um tema de interesse acadêmico e social relevante.

Esta pesquisa está estruturada em cinco capítulos, incluindo esta introdução. O segundo capítulo se dedica à revisão de literatura, a qual teve como base a discussão sobre a sociedade global de risco, a gestão socioambiental e os aspectos da pesquisa bibliométrica. No terceiro capítulo é definida a metodologia da pesquisa. Na quarta parte, são apresentados os resultados da pesquisa empírica e na quinta, e última etapa, são apresentadas as considerações finais. 


\section{REVISÃO DE LITERATURA}

\subsection{RISCO AMBIENTAL E O PARADIGMA DA GESTÃO SOCIOAMBIENTAL}

Segundo Beck (2010), do sucesso da atividade econômica e dos avanços científicotecnológicos, a sociedade atual passa a ser confrontada com as consequências e limites do seu próprio modelo de desenvolvimento. Vive-se um novo estágio de modernidade, em que a produção social da riqueza é sistematicamente acompanhada da produção social de riscos. Os riscos da modernidade passam a ser concebidos como resultados da ação (ir) racional do homem, que crescentemente ameaçam a sua própria existência sob todas as formas. Assim, se as ameaças sempre estiveram presentes na vida humana, os riscos imprevisíveis e a insegurança decorrente do processo de modernização constituem uma qualidade historicamente nova da sociedade.

Evidencia-se, sobretudo em matéria ambiental, a temática que orienta a abordagem desse estudo, que a natureza tem sido vítima da ação predatória e irresponsável do homem (BECK, 2010).

Nesse contexto, não em contradição, mas em complementação a avaliação de Beck (2010) destaca-se Tachizawa (2005), o qual assevera que se vive um novo paradigma organizacional, no qual as novas organizações são achatadas na estrutura, a estrutura perde importância e ganha destaque o posicionamento de áreas funcionais voltadas para o gerenciamento das questões de proteção ao meio ambiente e da responsabilidade social. A sociedade e as empresas já se deram conta que os sistemas naturais não são infinitos e, por isso, não são capazes de ilimitadamente absorver os efeitos da produção e do consumo. O paradigma atual das organizações impõe a adoção de uma dimensão ética do ambiente, reconduzindo-a para a lógica da responsabilidade, solidariedade e cooperação dos agentes envolvidos. Nesse sentido, é clara a necessidade de se promover mudanças no ambiente organizacional, desenvolvendo abordagens destinadas a lidar com crises ambientais e com uma nova postura dos clientes, cada vez mais interessados em interagir com empresas éticas, com imagem institucional positiva e que atuem de forma ecologicamente responsável (TACHIZAWA, 2005).

Esse desafio imposto pelos novos paradigmas, em um cenário onde o homem historicamente coloca em risco o planeta por suas próprias ações, é fértil para a discussão sobre práticas de gestão socioambiental, sobretudo no âmbito das organizações, principais responsáveis pela geração de resíduos poluentes que vêm, ao longo dos últimos séculos, afetando o ambiente e as pessoas que residem no planeta. 


\subsection{GESTÃO SOCIOAMBIENTAL E PEQUENAS EMPRESAS}

Nos termos preconizados por Tachizawa (2005), a globalização econômica, a internacionalização de problemas ambientais, a ação de grupos ambientais e de consumidores, os programas de selo verde e as exigências de setores econômicos caracterizam a primeira década deste século XXI. Atualmente, os gestores devem adequar suas práticas, para lidar com situações complexas envolvendo interesses conflitantes entre os mais diversos agentes sociais e econômicos, tais como: lucro, qualidade de serviços e produtos, preservação ambiental e proteção de direitos trabalhistas. Nesse contexto, as demandas por um processo de gestão socioambiental tornaram-se cada vez mais frequentes e, conforme preconizado por Seiffert (2014), atingindo, inclusive, empresas de micro e pequeno porte.

Apesar de todo o amadurecimento do processo de gestão ambiental no decorrer das últimas décadas, em especial a partir dos anos 90, deve-se reconhecer que os conceitos de desenvolvimento sustentável e de gestão ambiental ainda não assumiram uma configuração definitiva e de caráter consensual (SEIFFERT, 2014). Para a autora, a gestão ambiental busca a:

[...] condução harmoniosa dos processos dinâmicos e interativos que ocorrem entre os diversos componentes do ambiente natural e antrópico, determinados pelo padrão de desenvolvimento almejado pela sociedade. Para tanto, deve considerar a complexidade inerente aos ecossistemas antrópicos e suas inter-relações e interdependências dos ecossistemas naturais (SEIFFERT, 2014, p. 48).

Tachizawa (2005), por sua vez, evidencia um caráter mais amplo desse processo, para também envolver o aspecto social na nova postura gerencial exigida das organizações:

Gestão ambiental envolve a passagem do pensamento mecanicista para o pensamento sistêmico, no qual um aspecto essencial dessa mudança é que a percepção do mundo como máquina cede lugar à percepção do mundo como sistema vivo.

Assim, a gestão socioambiental deve expressar compromisso com a adoção e a difusão de valores, conduta e procedimentos que induzam e estimulem o contínuo aperfeiçoamento dos processos empresariais, para que se obtenha resultado tanto em preservação ambiental, quanto em melhoria da qualidade de vida da sociedade, conciliando os aspectos sociais e ambientais com aspectos econômicos e relacionados a sustentabilidade empresarial.

Nesse contexto que Barbieri (2007), visualiza duas grandes vertentes sobre o tema: de um lado, as posições antropocêntricas, nas quais a valorização da natureza encontra-se subordinada às necessidades humanas; de outro, as posições ecocêntricas, que defendem a 
equidade ecológica, de sorte que nenhum ser vivo, inclusive o humano, pode se sobrepor às demais espécies. Em meio a esses dois extremos, Barbieri (2007) evidencia a abordagem socioambiental, que é a perspectiva adotada nesse estudo, nos seguintes termos:

Entre os extremos antropocêntricos e ecocêntricos, encontram-se as abordagens socioambientais que reconhecem o valor intrínseco da natureza, mas admitem que ela deve ser usada para atender às necessidades humanas presentes e futuras e, por isso, buscam -se sistemas de produção e consumo sustentáveis e ecoeficientes. As propostas de gestão ambiental empresarial decorrentes dessa visão devem se apoiar em três critérios de desempenho, a saber: eficiência econômica, equidade social e respeito ao meio ambiente, critérios estes que devem ser considerados simultaneamente.

Logo, o processo de amadurecimento da gestão socioambiental, perpassa pelo entendimento que o meio-ambiente é prioritário e que a sua proteção, em vez de obstáculo, é em verdade mola propulsora ao desenvolvimento econômico (TENÓRIO, 2006). O processo de gestão ambiental, na visão de Seiffert (2014, p. 187), ganhou uma nova roupagem, "não só focalizando benefícios socioambientais gerados pelo melhor desempenho das organizações, como também enfatizando os benefícios econômicos resultantes disso [...]”. Evidencia-se, com isso, que o modelo de gestão socioambiental não tem por objetivo rejeitar o crescimento econômico das organizações, mas ante o contrário, desenvolver técnicas de gestão e produção que gerem economias, ecoeficiência melhora de produtividade e de resultados econômicos.

Aos gestores, portanto, de todas as organizações, de porte e finalidades distintas, impõese um grande desafio de adotar uma postura proativa e sistêmica, antecipando-se a degradação ambiental e à crises organizacionais, de modo a conciliar interesses aparentemente contraditórios: econômicos, sociais e ambientais. Trata-se de uma tendência irreversível imposta pelo próprio mercado, formado por stakeholders mais exigentes, conscientes e seletivos por produtos e serviços, que não só representem menor impacto ambiental, mas que também gerem maiores ganhos sociais e econômicos.

Nesse cenário, merecem destaque as pequenas empresas brasileiras, compreendido no conjunto de microempresas (ME), empresas de pequeno porte (EPP) e microempreendedores individuais (MEI), que, segundo pesquisa do Serviço Brasileiro de Apoio às Micro e Pequenas Empresas - SEBRAE (2014) realizada em 2012, já demonstram iniciar uma mudança de posicionamento para lidar com as questões ambientais. Segundo a pesquisa, cujo universo abrangeu 3.912 entrevistados em todo o país, cerca de 75,2\% dos pequenos empresários reconhecem o alto grau de importância que deve ser atribuído à questão do meio ambiente. E não só isso: a maioria dos empresários consultados afirmou adotar práticas sustentáveis no dia 
a dia de suas empresas, a exemplo de: coleta seletiva de lixo $(70,2 \%)$, controle do consumo de papel $(72,4 \%)$, controle do consumo de água $(80,6 \%)$ e controle do consumo de energia $(81,7 \%)$. Apesar disso, a pesquisa evidenciou que ainda é necessário esclarecer aos pequenos empresários sobre as oportunidades que o tema sustentabilidade pode gerar ao negócio, uma vez que apenas $46 \%$ deles vislumbra oportunidades de ganhos; ao passo que para $38 \%$ é indiferente aos resultados que a questão ambiental pode representar para a sua empresa, isto é, para eles, não implicaria nem ganhos, nem despesas.

Ainda sobre os pequenos negócios, é importante destacar que, dada a sua capilaridade e participação na economia brasileira, com significativa influência na geração de emprego e renda, põe em pauta a discussão sobre a sua postura frente às demandas socioambientais da sociedade.

\subsection{BIBLIOMETRIA}

Para Machado, Barbosa e Quintana (2011), a bibliometria destaca-se por revelar informações sobre a produção científica realizada e sobre os aspectos importantes tratados, agregando assim conhecimento que pode ser explorado tanto pelas novas publicações que almejam tratar sobre tais assuntos, quanto pelas que pretendem tratar sobre assuntos ainda não explorados.

Na visão de Alvarenga e Araújo (2011), a bibliometria, como área de estudo da ciência da informação, representa uma função relevante na investigação, exploração e produção científica de um país.

Particularmente, no campo das ciências sociais aplicadas os estudos bibliométricos se concentram em examinar a produção de artigos em um determinado campo de saber, mapear as comunidades acadêmicas e identificar as redes de pesquisadores e suas motivações. Tais objetivos são tangibilizados por meio da criação de indicadores que buscam sumarizar as instituições e os autores mais prolíferos, os acadêmicos mais citados e as redes de coautorias (OKUBO, 1997).

\section{ENCONTRO DE ESTUDOS SOBRE EMPREENDEDORISMO - EGEPE}

O EGEPE - Encontro de Estudos sobre Empreendedorismo e Gestão de Pequenas Empresas, é um evento consolidado no país e se firma como o principal espaço para o debate sobre empreendedorismo e gestão de pequenas empresas, nas áreas da administração, 
contabilidade e turismo. O evento e realizado a cada dois anos e teve início no ano de 2000 . Em 2011, com a criação da Associação Nacional de Estudos em Empreendedorismo e Gestão de Pequenas Empresas - ANEGEPE, esta assumiu a sua realização. Até o presente momento, nove edições já foram realizadas, sendo a última em 2016 (IX EGEPE). Assim, o EGEPE passou a representar uma comunidade de pesquisa, sendo o principal espaço para o debate das áreas de empreendedorismo e gestão de pequenas empresas no Brasil (EGEPE, 2018).

O EGEPE tem por objetivo principal promover o desenvolvimento de conhecimento e divulgar o empreendedorismo no país através de discussão de temas emergentes como: novas configurações das pequenas e médias empresas e das pequenas propriedades rurais; empresas familiares e agricultura familiar; o ensino do empreendedorismo na educação básica, o modelo de negócio, as alianças, as redes e a cooperação estratégica; a internacionalização de pequenas e médias empresas, motivações, barreiras e modos de entrada; o contexto das pequenas propriedades rurais e suas configurações; as competências e formas de operar das pequenas e médias empresas para co-criação de valor; as perspectivas de crescimento das pequenas e médias empresas em um ambiente de inovação e transferência de tecnologia; a formação empreendedora e as perspectivas para o mercado (EGEPE, 2018).

Dessa forma, critica-se o EGEPE por ter uma linha específica que estimule o debate sobre a gestão socioambiental no nível das pequenas empresas brasileiras. Ainda assim, certamente é o maior evento e vetor direcionado para o debate as que envolve.

\section{METODOLOGIA}

Utilizando a taxonomia de Farias Filho e Arruda Filho (2013), quanto aos objetivos, trata-se de uma pesquisa descritiva, quanto aos procedimentos técnicos trata-se de uma pesquisa documental, na qual serão utilizadas informações contidas em documentos que ainda não passaram por uma análise aprofundada no sentido do que se busca, com abordagem quantiqualitativa do problema de pesquisa, uma vez que, além de mensurar os elementos principais da bibliometria, pretende-se investigar qualitativamente os principais pontos discutidos nos trabalhos apresentados.

Nesse estudo, os documentos foram buscados nos Anais dos Encontros de Estudos sobre Empreendedorismo e Gestão de Pequenas Empresas - EGEPE, em nove edições realizadas no período de 2000 a 2016, disponíveis no sítio http://egepe.org.br/anais/index.php. Para localizar os artigos que abordam o tema gestão socioambiental foi utilizada uma busca, com as seguintes 
palavras-chave: sustentabilidade, gestão social, gestão ambiental, gestão socioambiental, meio ambiente e responsabilidade social.

Para a realização da pesquisa, primeiramente foram identificados os artigos publicados a respeito do tema gestão socioambiental; em seguida, os artigos selecionados foram quantificados para levantamento da tendência de publicação, quantidade de autores, quantidade de autores por artigo, assim como, a instituição ao qual os mesmos são vinculados, o lócus da pesquisa, o setor e a atividade preponderante.

Do ponto de vista qualitativo, foi realizada análise de conteúdo. Foram analisados os objetivos, a metodologia e os resultados encontrados, por meio da leitura dos artigos. Dessa forma, complementando a análise bibliométrica na busca de novos parâmetros para o favorecimento e o desenvolvimento da pesquisa na área de conhecimento.

\section{RESULTADOS DA PESQUISA}

\subsection{RESULTADO QUANTITATIVO DOS TRABALHOS PUBLICADOS}

Da população inicial de artigos publicados nos anais do Evento no total de 771 , foram identificados 21 trabalhos, conforme apresentado na Tabela 1:

Tabela 1 - Publicação em gestão socioambiental nos Anais do EGEPE

\begin{tabular}{|lcccccccccc|}
\hline ÁREA & $\mathbf{2 0 0 0}$ & $\mathbf{2 0 0 1}$ & $\mathbf{2 0 0 3}$ & $\mathbf{2 0 0 5}$ & $\mathbf{2 0 0 8}$ & $\mathbf{2 0 1 0}$ & $\mathbf{2 0 1 2}$ & $\mathbf{2 0 1 4}$ & $\mathbf{2 0 1 6}$ & TOTAL \\
\hline Sustentabilidade & - & - & - & - & 01 & - & - & 03 & 04 & 08 \\
Gestão Ambiental & - & - & 01 & - & - & 02 & 02 & 01 & - & 06 \\
Gestão Social & - & - & - & - & - & - & - & - & - & 00 \\
Gestão Socioambiental & - & - & - & - & - & - & 01 & - & - & 01 \\
Meio Ambiente & - & 01 & - & - & - & - & - & - & - & 01 \\
Responsabilidade Social & - & 01 & - & 01 & - & - & 03 & - & - & 05 \\
\hline TOTAL & $\mathbf{0 0}$ & $\mathbf{0 2}$ & $\mathbf{0 1}$ & $\mathbf{0 1}$ & $\mathbf{0 1}$ & $\mathbf{0 2}$ & $\mathbf{0 6}$ & $\mathbf{0 4}$ & $\mathbf{0 4}$ & $\mathbf{2 1}$ \\
\hline
\end{tabular}

Fonte: Anais do EGEPE.

Esse resultado mostra o quanto o assunto, de tão grande relevância, necessita ganhar força no âmbito das ciências de gestão. Durante o período o EGEPE, 771 artigos foram apresentados e, desses, 21 discutem a temática relacionada à sustentabilidade e à gestão socioambiental, em percentual de $2,7 \%$ do total de artigos apresentados. Em exame aos dados coletados, verifica-se que, no período de 2000 a 2010, foram apresentados sete artigos, aumentando o interesse pela pesquisa a partir do ano de 2012, quando foram apresentados seis artigos, e nos anos de 2014 e 2106 foram apresentados quatro artigos em cada edição. De certa 
forma, pode-se dizer que houve um aumento do interesse em pesquisar o tema, mas certamente ainda há muito espaço para pesquisas na área.

Observa-se que 2012 foi o ano com a maior quantidade de publicações em gestão socioambiental de todas as edições do EGEPE, com a apresentação de seis artigos. Possivelmente, o fato tenha decorrido por conta de alguns acontecimentos na área ambiental que marcaram o período, a exemplo da publicação do novo Código Florestal (Lei 12.651 de 25 de maio de 2012) e a realização da Conferencia das Nações Unidas sobre desenvolvimento natural, conhecida também como Rio +20, nos dias 13 a 22 de junho. Além disso, o EGEPE 2012 teve como temas principais a internacionalização e a sustentabilidade.

Dessa observação inicial, pretendeu-se analisar à origem dos artigos publicados, em especial no que se refere às Instituições de Ensino às quais os pesquisadores encontravam-se vinculados e, por consequência, os estados e regiões com maiores publicações, no que ser levantou o seguinte, conforme apresentado na Tabela 2.

Observa-se analisando as publicações de acordo com suas Instituições de Origem, que não foi possível perceber uma tendência de pesquisa, não foi possível perceber nenhum núcleo de estudos e pesquisas que evidenciasse no período, mais de dois trabalhos publicados, ou seja, os resultados transparecem que as pesquisas foram publicadas de forma aparentemente aleatória pelas instituições de pesquisa ao longo dos anos, sem vínculos à núcleos ou projetos de pesquisa com essa finalidade. Ao total foram identificadas 25 instituições de ensino de autores e coautores. Foi possível identificar que as instituições preponderantes onde se pesquisa a temática são as Universidades Públicas, as quais abrigam 68\% dos autores dos trabalhos publicados. 
Tabela 2 - Artigos publicados nos Anais do EGEPE - Por Instituição

\begin{tabular}{|c|c|c|c|c|c|c|c|c|c|c|}
\hline $\begin{array}{l}\text { INSTITUIÇÃO DE } \\
\text { ENSINO }\end{array}$ & 2000 & 2001 & 2003 & 2005 & 2008 & 2010 & 2012 & 2014 & 2016 & TOTAL \\
\hline UEM/UEL & - & 01 & 01 & - & - & - & - & - & - & 02 \\
\hline UFS & - & 01 & - & - & - & - & - & 01 & - & 02 \\
\hline FADE/UNIVALI & - & - & - & 01 & - & - & - & - & - & 01 \\
\hline UFRS & - & - & - & - & 01 & - & - & - & - & 01 \\
\hline UFPE/UFRPE & - & - & - & - & - & 01 & - & - & - & 01 \\
\hline UDESC/UFBA & - & - & - & - & - & 01 & - & - & - & 01 \\
\hline UNIOESTE & - & - & - & - & - & - & 01 & - & 01 & 02 \\
\hline UFPel & - & - & - & - & - & - & 01 & - & - & 01 \\
\hline UNIVALI & - & - & - & - & - & - & 01 & - & - & 01 \\
\hline UCSal & - & - & - & - & - & - & 01 & - & - & 01 \\
\hline FURB/UNISUL & - & - & - & - & - & - & 01 & - & - & 01 \\
\hline UNIFRA/UFSM & - & - & - & - & - & - & 01 & - & - & 01 \\
\hline UFG & - & - & - & - & - & - & - & 01 & - & 01 \\
\hline FIS/UFSC & - & - & - & - & - & - & - & 01 & - & 01 \\
\hline UNIFOR & - & - & - & - & - & - & - & 01 & - & 01 \\
\hline UPF & - & - & - & - & - & - & - & - & 01 & 01 \\
\hline UNOESC & - & - & - & - & - & - & - & - & 01 & 01 \\
\hline UMA & - & - & - & - & - & - & - & - & 01 & 01 \\
\hline TOTAL & 00 & 02 & 01 & 01 & 01 & 02 & 06 & 04 & 04 & 21 \\
\hline
\end{tabular}

Fonte: Anais do EGEPE.

Legenda: Universidade Estadual de Maringá (UEM), Universidade Estadual de Lobdrina (UEL), Universidade Federal de Sergipe (UFS), Faculdade Decisão (FADE), Universidade do Vale do Itajaí (UNIVALI), Universidade Federal do Rio Grande do Sul (UFRS), Universidade Federal de Pernambuco (UFPE), Universidade Federal Rural de Pernambuco (UFRPE), Universidade do Estado de Santa Catarina (UDESC), Universidade Federal da Bahia (UFBA), Universidade Estadual do Oeste do Paraná (UNIOESTE), Universidade Federal de Pelotas (UFPel), Universidade Católica do Salvador (UCSal), Fundação Universidade de Blumenau (FURB), Fundação Universidade do Sul de Santa Catarina (UNISUL), Centro Universitário Franciscano (UNIFRA), Universidade Federal de Santa Maria (UFSM), Universidade Federal de Goiás (UFG), Faculdade de Integração do Sertão (FIS), Universidade Federal de Santa Catarina (UFSC), Universidade de Fortaleza (UNIFOR), Universidade de Passo Fundo (UPF), Universidade do Oeste de Santa Catarina (UNOESC) e Centro Universitário UNA (UNA).

Na próxima tabela mostrar-se-á, como as pesquisas estão distribuídas por estado. Na tabela 3, percebe-se uma leve tendência de desenvolvimento de pesquisa relacionado ao tema socioambiental nos estados do Paraná, Rio Grande do Sul e Santa Catarina, sendo quatro publicações para os estados do Paraná e Rio Grande do Sul e cinco publicações para o estado de Santa Catarina dentro das nove edições do encontro EGEPE, evidenciando uma maior concentração de trabalhos na região Sul do Brasil. 
Tabela 3 - Artigos publicados nos Anais do EGEPE - Por Estado

\begin{tabular}{lcccccccccc}
\hline Estados & $\mathbf{2 0 0 0}$ & $\mathbf{2 0 0 1}$ & $\mathbf{2 0 0 3}$ & $\mathbf{2 0 0 5}$ & $\mathbf{2 0 0 8}$ & $\mathbf{2 0 1 0}$ & $\mathbf{2 0 1 2}$ & $\mathbf{2 0 1 4}$ & $\mathbf{2 0 1 6}$ & TOTAL \\
\hline Bahia* & - & - & - & - & - & 01 & 01 & - & - & 02 \\
Ceará & - & - & - & - & - & - & - & 01 & - & 01 \\
Goiás & - & - & - & - & - & - & - & 01 & - & 01 \\
Minas Gerais & - & - & - & - & - & - & - & - & 01 & 01 \\
Paraná & - & 01 & 01 & - & - & - & 01 & - & 01 & 04 \\
Pernambuco & - & - & - & 01 & - & 01 & - & - & - & 02 \\
Rio De Janeiro* & - & - & - & - & - & - & - & 01 & - & 01 \\
Rio Grande Do Sul & - & - & - & - & 01 & - & 02 & - & 01 & 04 \\
Santa Catarina* & - & - & - & - & - & 01 & 02 & 01 & 01 & 05 \\
Sergipe & - & 01 & - & - & - & - & - & 01 & - & 02 \\
\hline Total & $\mathbf{0 0}$ & $\mathbf{0 2}$ & $\mathbf{0 1}$ & $\mathbf{0 1}$ & $\mathbf{0 1}$ & $\mathbf{0 3}$ & $\mathbf{0 6}$ & $\mathbf{0 5}$ & $\mathbf{0 4}$ & $\mathbf{2 3}$ \\
\hline
\end{tabular}

Fonte: Anais do EGEPE

* 2010 - Um artigo foi feito em parceria entre Bahia e Santa Catarina

* 2014 - Um artigo foi feito em parceria entre Rio de Janeiro e Santa Catarina

Complementando a análise, observando a tabela 4, a região Sul desponta como a região com mais pesquisas na área, seguida da região Nordeste. A região Norte não apresenta nenhum artigo publicado na área.

Tabela 4 - Artigos publicados nos Anais do EGEPE - Por Região.

\begin{tabular}{|l|c|}
\hline \multicolumn{1}{|c|}{ Região } & Quantidade \\
\hline Norte & 00 \\
\hline Nordeste* $^{*}$ & 07 \\
\hline Centro-Oeste & 01 \\
\hline Sudeste* & 02 \\
\hline Sul* & 13 \\
\hline Total & $\mathbf{2 3}$ \\
\hline
\end{tabular}

Fonte: Anais do EGEPE

*2010 - Um artigo foi feito em parceria entre Bahia e Santa Catarina

*2014 - Um artigo foi feito em parceria entre Rio de Janeiro e Santa Catarina

A Tabela 4 demonstra, por região, como estão distribuídas as produções científicas publicadas nos anais do EGEPE. Como já mencionado anteriormente, a região sul destaca-se com 13 publicações, seguida da região Nordeste com sete publicações. Vale ressaltar que essa análise está considerando a Instituição de Ensino as quais os autores estão vinculados. Dessa forma percebe-se que a temática gestão socioambiental, nas micro e pequenas empresas, ainda vem sendo tratado com bastante timidez pelos micro e pequenos empresários. 


\subsection{RESULTADO QUALITATIVO DOS TRABALHOS PUBLICADOS}

A partir da análise de conteúdo realizada, podem-se agrupar as pesquisas em algumas categorias afins:

1) a realização de práticas de gestão socioambiental pelas empresas;

2) a percepção dos empreendedores sobre a importância da adoção de práticas de gestão socioambiental;

3) as vantagens econômicas decorrentes da adoção de práticas de gestão socioambiental;

4) políticas de incentivos a adoção de práticas de gestão socioambiental.

Como primeiro ponto, em relação a realização de práticas de gestão socioambiental, cabe destacar o trabalho de Aligleri e Prevideli (2001), o qual teve como objetivo discutir a responsabilidade social realizada pelas pequenas empresas. Na mesma linha, as pesquisas de Passos e Camara (2003), Karkotti, Ferreira e Souza (2005), Nogueira (2012), Sousa, Silva, Rabelo Neto e Sousa (2014) e Sanches e Schimidt (2016), as quais tiveram como objetivo analisar as práticas (correntes ou estratégicas) de sustentabilidade social e ambiental realizadas pelos empreendimentos. Como resultados, os mesmos convergem para a não adoção de estratégias formais de ações de responsabilidade socioambiental, tampouco para a adoção sistemática de ações de gestão socioambiental. As ações são realizadas de forma não sistemática, e embora estejam evoluindo. Pode-se afirmar que existem iniciativas de sustentabilidade ambiental, principalmente, no que tange aos ecossistemas água e uso de recursos. Os empreendedores estão se preocupando com as questões de sustentabilidade ambiental, e uma certa consciência para sustentabilidade tem surgido entre os pequenos empreendedores, mas ainda falta comprometimento para alcançar melhores resultados.

Como segundo ponto, a percepção dos empreendedores sobre a importância da adoção de práticas de gestão socioambiental, destacam-se os artigos de Barbosa e Teixeira (2001), e Arruda (2016), os quais levantaram que os micro e pequenos empresários não se percebem como poluidores, desconhecem a forma de colocar em prática ações de natureza socioambiental, representando um desafio internalizar a consciência de sustentabilidade no dia a dia dos empreendedores.

O terceiro ponto que se destaca na análise dos textos são as vantagens econômicas decorrentes da adoção de práticas de gestão socioambiental. Nesse quesito podem-se destacar as pesquisas de Trindade (2012), Scharf, Orlandi e Fernandes (2012), Santos Júnior e Olave (2014), Oliveira e Rosseto (2014) e Salvia, Pilonetto e Brandli (2016), as quais evidenciaram 
que a implantação da gestão ambiental passou a ser um componente estratégico na redução dos custos e busca de eficiência, e também utilizada estrategicamente para a melhora da imagem organizacional. A questão competitividade também foi mencionada como elemento de estímulo para a adoção de estratégias de gestão socioambiental pelas empresas.

Nesse quesito se destaca a tendência recente de pesquisa envolvendo a questão da gestão socioambiental como estratégia nas MPEs.

O quarto e último ponto destacado são as políticas de incentivos a adoção de práticas de gestão socioambiental por parte do governo. Três pesquisas destacaram esse ponto: Barbosa, Teixeira (2001), El-Deir e colaboradores (2010) e Oliveira e Rosseto (2014). Nesse sentido autores avaliam a interferência do governo no estabelecimento de metas ambientais a serem cumpridas pelas empresas e ainda no estabelecimento de políticas de incentivo para a adoção de ações de natureza socioambiental.

Assim, como resultados, de um modo geral, os autores obtiveram como resposta que a geração de uma cultura organizacional de comprometimento de todos os colaboradores da organização é muito importante para que sejam realizadas ações socioambientais na organização, e, nesse sentido, os resultados das pesquisas apontam que tem havido evolução nas ações de natureza socioambiental entre as micros e pequenas empresas, as quais contribuem positivamente para melhorar a imagem da organização e acrescentando-lhe um diferencial competitivo (ALIGLERI; PREVIDELI, 2001; PASSOS; CAMARA, 2003; KARKOTLI; FERREIRA; SOUZA, 2005; SOUSA et al., 2014; SANCHES; SCHIMIDT, 2016).

\section{CONSIDERAÇÕES FINAIS}

Primeiramente o presente estudo demonstra que as pesquisas em gestão socioambiental voltadas para as micro e pequenas empresas necessitam ganhar força, a exemplo do que já se vem pesquisando para médias e grandes empresas. É importante que temas relacionados a gestão socioambiental possam ser mais discutidos em congressos e universidades, relatando a experiência das empresas, a exemplo do Encontro de Estudos sobre Empreendedorismo e Gestão de Pequenas Empresas-EGEPE. A

Dentro desse contexto, o EGEPE serviu de base para a pesquisa, onde foi possível analisar, no período de 2000 até 2016, os artigos publicados no encontro que estão relacionados com o tema. Sob o ponto de vista quantitativo, os resultados observados, mostram que o tema ainda tem sido pouco discutido no âmbito das micro e pequenas empresas, mas vem ganhando força, onde destacam-se as instituições de ensino superior públicas, notadamente da região sul 
do Brasil, como as mais produtivas no tema. Sob o ponto de vista qualitativo foram identificadas quatro categorias de análise, a realização de práticas de gestão socioambiental pelas empresas; a percepção dos empreendedores sobre a importância da adoção de práticas de gestão socioambiental; as vantagens econômicas decorrentes da adoção de práticas de gestão socioambiental; políticas de incentivos a adoção de práticas de gestão socioambiental, observada a tendência recente de estudar as MPEs sob a ótica da estratégia em implantar ações de natureza socioambiental.

Entende-se que o EGEPE deve destinar uma linha específica dentro do encontro voltada para a gestão socioambiental, para maior discussão de práticas sustentáveis dentro das organizações, gerando maior conhecimento acadêmico e interação social para maior conscientização por parte de micro e pequenos empreendedores, governo, consumidores e demais stakeholders.

O estudo aponta algumas limitações, tais como, a aplicação da pesquisa em um único encontro e amostra reduzida utilizada na análise dos dados. Assim, como sugestão, o envolvimento de outros congressos e periódicos para ampliação do conhecimento sobre o tema. 


\section{REFERÊNCIAS}

ALIGLERI, Lilian Mara; PREVIDELI, José de Jesus. Responsabilidade Social na Pequena Empresa como Alternativa de Gestão Empresarial. In: ENCONTRO DE ESTUDOS DOBRE EMPREENDEDORISMO E GESTÃO DE PEQUENAS EMPRESAS (EGEPE), 2.,2001, Londrina. Anais eletrônicos...Londrina: EGEPE, 2001. Disponível em:

$<$ http://egepe.org.br/anais/index.php>.Acesso em: 13/06/2018.

ARRUDA, Cristiane Duarte. A sustentabilidade sob a ótica de mulheres empreendedoras do oeste catarinense. In: ENCONTRO DE ESTUDOS DOBRE EMPREENDEDORISMO E GESTÃO DE PEQUENAS EMPRESAS (EGEPE), 9.,2016, Passo Fundo. Anais eletrônicos...Passo Fundo: EGEPE, 2016. Disponível em: $<$ http://egepe.org.br/anais/index.php >.Acesso em: 13/06/2018.

BARBIERI, José Carlos. Gestão ambiental empresarial: conceitos, modelos e instrumentos. São Paulo: Saraiva, 2007.

BARBOSA, Jenny Dantas; TEIXEIRA, Rivanda Meira. A percepção dos empresarios sobre impactos ambientais: O caso das pequenas e médias empresas. In: ENCONTRO DE ESTUDOS DOBRE EMPREENDEDORISMO E GESTÃO DE PEQUENAS EMPRESAS (EGEPE), 2.,2001, Londrina. Anais eletrônicos...Londrina: EGEPE, 2001. Disponível em: <http://egepe.org.br/anais/index.php>.Acesso em: 13/06/2018.

BECK, Ulrich. Sociedade de risco: rumo a uma outra modernidade. Tradução: Sebastião Nascimento. São Paulo: Ed. 34, 2010.

EL-DEIR, et al. Epaminondas Luiz Borges. Gestão Ambiental em Micro e Pequenas Empresas, uma proposta metodológica. In: ENCONTRO DE ESTUDOS DOBRE EMPREENDEDORISMO E GESTÃO DE PEQUENAS EMPRESAS (EGEPE), 6.,2010, Recife. Anais eletrônicos...Recife: EGEPE, 2010. Disponível em: $<$ http://egepe.org.br/anais/index.php $>$.Acesso em: 13/06/2018.

FARIAS FILHO, Milton Cordeiro; ARRUDA FILHO, Emilio J. M. Planejamento da Pesquisa Científica. São Paulo: ed. Atlas 2013.

SANTOS JUNIOR, José Evanlito dos; OLAVE, Maria Elena Leon. A Gestão Ambiental e os seus Benefícios Econômicos: Um estudo de caso na Usina de Beneficiamento de laticínios Santa Maria Ltda. In: ENCONTRO DE ESTUDOS DOBRE EMPREENDEDORISMO E GESTÃO DE PEQUENAS EMPRESAS (EGEPE), 8.,2014, Goiânia. Anais eletrônicos...Goiânia: EGEPE, 2014. Disponível em:<http://egepe.org.br/anais/index.php>.Acesso em: 13/06/2018.

KARKOTLI, Gilson R.; FERREIRA, Elaine; SOUZA, Maria José Barbosa de. Responsabilidade Social: uma estratégia Empreendedora para pequenas empresa. In: ENCONTRO DE ESTUDOS DOBRE EMPREENDEDORISMO E GESTÃO DE PEQUENAS EMPRESAS (EGEPE), 4.,2005, Curitiba. Anais eletrônicos...Curitiba: EGEPE, 2005. Disponível em:<http://egepe.org.br/anais/index.php>.Acesso em: 13/06/2018.

MACHADO, D. G.; BARBOSA, D. S.; QUINTANA, A. C. Análise da Produção Científica sobre os Fluxos de Caixa e a Demonstração dos Fluxos de Caixa: um estudo da Revista de 
Contabilidade e Finanças da Universidade de São Paulo, no período de 1989 a 2009. Revista Enfoque: Reflexão Contábil, v. 30, n. 2, p. 52-66, 2011.

NOGUEIRA, Maria da Graça Saraiva. Instituição de Ensino Superior: Uma visão sobre a Responsabilidade Social Corporativa Pública como ferramenta de vantagem competitiva e estratégia de expansão. In: ENCONTRO DE ESTUDOS DOBRE EMPREENDEDORISMO E GESTÃO DE PEQUENAS EMPRESAS (EGEPE), 7.,2012, Florianópolis. Anais eletrônicos...Florianópolis: EGEPE, 2012. Disponível em:<http://egepe.org.br/anais/index.php>.Acesso em: 13/06/2018.

OKUBO, Y. "Bibliometric Indicators and Analysis of Research Systems: Methods and Examples”, OECD Science, Technology and Industry Working Papers, 1997/01, OECD Publishing.Systems, 1997. Acesso em: 14/06/2018. Disponível em: <http://dx.doi.org/10.1787/208277770603>.

OLIVEIRA, Murilo de Alencar Souza; ROSSETTO, Adriana Marques. Influência dos fatores externos na Decisão Estratégica em sustentabilidade nas Pequenas Empresas Hoteleiras. In: ENCONTRO DE ESTUDOS DOBRE EMPREENDEDORISMO E GESTÃO DE PEQUENAS EMPRESAS (EGEPE), 8.,2014, Goiânia. Anais eletrônicos...Goiânia: EGEPE, 2014. Disponível em:<http://egepe.org.br/anais/index.php>.Acesso em: 13/06/2018.

PASSOS, Luis Antônio Niro; CAMARA, Marcia Regina Gabardo. Evolução da Gestão Ambiental em Empresas Industriais: Um estudo nas pequenas e médias empresas do setor químico. In: ENCONTRO DE ESTUDOS DOBRE EMPREENDEDORISMO E GESTÃO DE PEQUENAS EMPRESAS (EGEPE), 3.,2003, Brasília. Anais eletrônicos...Brasília: EGEPE, 2003. Disponível em:<http://egepe.org.br/anais/index.php>.Acesso em: 13/06/2018.

SALVIA, Amanda Lage; PILONETTO, Iuna; BRANDLI, Luciana. Desafios na aplicação da sustentabilidade no setor elétrico brasileiro. In: ENCONTRO DE ESTUDOS DOBRE EMPREENDEDORISMO E GESTÃO DE PEQUENAS EMPRESAS (EGEPE), 9.,2016, Passo Fundo. Anais eletrônicos...Passo Fundo: EGEPE, 2016. Disponível em:<http://egepe.org.br/anais/index.php>.Acesso em: 13/06/2018.

SANCHES, Fernanda Cristina; SCHIMIDT, Carla Maria. Indicadores de Sustentabilidade Ambiental: Uma análise das práticas sustentáveis em empreendimentos de turismo rural. In: ENCONTRO DE ESTUDOS DOBRE EMPREENDEDORISMO E GESTÃO DE PEQUENAS EMPRESAS (EGEPE), 9.,2016, Passo Fundo. Anais eletrônicos...Passo Fundo: EGEPE, 2016. Disponível em:<http://egepe.org.br/anais/index.php>.Acesso em: 13/06/2018.

SCHARF, Edson Roberto; ORLANDI, Orlandy; FERNANDES, Josiane. Gestão Ambiental como estratégia de Marketing em uma empresa de Turismo Rural. In: ENCONTRO DE ESTUDOS DOBRE EMPREENDEDORISMO E GESTÃO DE PEQUENAS EMPRESAS (EGEPE), 7.,2012, Florianópolis. Anais eletrônicos...Florianópolis: EGEPE, 2012. Disponível em:<http://egepe.org.br/anais/index.php>.Acesso em: 13/06/2018.

SEBRAE. Serviço Brasileiro de Apoio às Micro e Pequenas Empresas. O que pensam as micro e pequenas empresas sobre sustentabilidade. Sebrae, 2012. Disponível em: < http://www.bibliotecas.sebrae.com.br/chronus/ARQUIVOS_CHRONUS/ bds/bds.nsf/ 1C7B72252F68A728832579F30068BDF3/\$File/NT00047606.pdf>Acesso em 15 jan. 2018. 
SEBRAE. Serviço Brasileiro de Apoio às Micro e Pequenas Empresas. Participação das Micro e Pequenas Empresas na Economia Brasileira. Sebrae, 2014. Disponível em: http://www.sebrae.com.br/Sebrae/Portal\%20Sebrae/Estudos\%20 e\%20Pesquisas/ Participacao\%20das\%20micro\%20e\%20pequenas\%20empresas.pdf. Acesso em 15 jan. 2018.

SEBRAE. Serviço Brasileiro de Apoio às Micro e Pequenas Empresas. Perfil das pequenas empresas e empresas de pequeno porte. Sebrae, 2018. Disponível em: < http://www.sebrae.com.br/Sebrae/Portal\%20Sebrae/UFs/RO/Anexos/Perfil\%20das\%20ME\% 20e\%20EPP\%20-\%2004\%202018.pdf. Acesso em 15 jan. 2018.

SEIFFERT, Mari Elizabete Bernardini. Gestão ambiental: instrumentos, esferas de ação e educação ambiental. São Paulo: Atlas, 2014.

SOUSA, Antônia Márcia Rodrigues, et al. Rompendo a Fronteira do Empreendedorismo: Uma experiência de educação e sustentabilidade socioambiental no Estado do Pará. In: ENCONTRO DE ESTUDOS DOBRE EMPREENDEDORISMO E GESTÃO DE PEQUENAS EMPRESAS (EGEPE), 8.,2014, Goiânia. Anais eletrônicos...Goiânia: EGEPE, 2014. Disponível em: $<$ http://egepe.org.br/anais/index.php>. Acesso em: 13/06/2018.

TACHIZAWA, Takeshy. Gestão ambiental e responsabilidade social corporativa: estratégias de negocios focados na realidade brasileira. São Paulo: Atlas, 2005.

TENÓRIO, Fernando Guilherme. Responsabilidade Social Empresarial - Teoria e Prática. Rio de Janeiro: Ed. FGV, 2006.

TRINDADE, Josefa Delm ada. Gestão Socioambiental no consumo responsável no empreendedorismo sustentável. In: ENCONTRO DE ESTUDOS DOBRE EMPREENDEDORISMO E GESTÃO DE PEQUENAS EMPRESAS (EGEPE), 7.,2012, Florianópolis. Anais eletrônicos...Florianópolis: EGEPE, 2012. Disponível em: $<$ http://egepe.org.br/anais/index.php>.Acesso em: 13/06/2018. 